\title{
Uncontrolled Agitation and Flushed Face Due to Tropicamide: A Missed Diagnosis
}

\author{
Ahmet Kağan Özkaya', Sinem Sarı Gökay², Özlem Tolu Kendir², Rıza Dinçer Yıldızdaş3, Hayri Levent Yılmaz² \\ 'Division of Pediatric Emergency Unit, Department of Pediatrics, Karadeniz Technical University School of Medicine, Trabzon, Turkey \\ 2Department of Pediatric Emergency, Cukurova University School of Medicine, Adana, Turkey \\ ${ }^{3}$ Department of Pediatric Intensive Care, Çukurova University School of Medicine, Adana, Turkey
}

Cite this article as: Özkaya AK, Sarı Gökay S, Tolu Kendir Ö, Yıldıztaş RD, Yılmaz HL. Uncontrolled Agitation and Flushed Face Due to Tropicamide: A Missed Diagnosis. J Emerg Med Case Rep 2017; 8: 59-61.

\begin{abstract}
Introduction: Topical ophthalmic drugs that are not used in appropriate doses may lead to overdose symptoms.

Case Report: A 2-month-old boy presented to the emergency department with extreme agitation, flushed face, mydriasis, cataract in the left eye, dry oral mucosa, spasticity in all extremities, and wheezing. It was learned that the patient had been receiving eye drops containing tropicamide at repeated doses before ophthalmologic evaluation. Pheniramine maleate and methylprednisolone were given to counter the drug-related side-effects or allergic reactions to the eye drop. At the follow-up, his symptoms and findings had become exacerbated, and he was admitted to the pediatric intensive care unit due to shock and drug-related anticholinergic toxicity.

Conclusion: This case illustrates the importance of recognizing toxidromes at differential diagnosis and is the first reported pediatric case with tropicamide-induced anticholinergic syndrome.
\end{abstract}

Keywords: Anticholinergic syndrome, tropicamide, children

Received: 05.08.2016 Accepted: 25.10.2016 Available Online Date: 15.02.2017

\section{Introduction}

Tropicamide is a well-known short-acting mydriatic and cycloplegic ophthalmic agent used in eye examinations and therapeutic applications in both adults and children. It is therefore widely used by clinicians. Tropicamide blocks muscarinic receptors in the peripheral and central nervous system and muscles, with actions similar to those of atropine. Adverse effects and toxicity associated with tropicamide occur because of its anticholinergic property. However, the anticholinergic syndrome may develop very rarely. Initially, the recognition of toxidromes by clinicians is essential for the treatment of the anticholinergic syndrome. We report a case of a child initially administered an antihistaminic agent for allergic drug reactions, with anticholinergic toxidrome induced by tropicamide.

\section{Case Report}

A 2-year-old boy presented to our pediatric emergency department with flushing of the face and uncontrolled agitation. Medical history revealed that the patient had been receiving eye drops containing 1\% tropicamide at 10-min intervals for $1 \mathrm{~h}, 3 \mathrm{~h}$ before ophthalmologic evaluation. The patient's mother noted that agitation occurred within 30 min of eye drop administration. The patient was currently under the care of our pediatric neurology department for epilepsy and cerebral palsy and was under a treatment regime of $5 \mathrm{mg} / \mathrm{kg} /$ day topiramate. It was also determined that the patient had been experiencing rhinorrhea and cough symptoms for 3 days but had no fever. Physical examination revealed that the body temperature was $36.7^{\circ} \mathrm{C}$, pulse 120 beats/min, blood pressure 120/80 mmHg, and respiratory rate 30 breaths/min, with uncontrolled agitation, mydriasis in both eyes,

This study was presented at the $12^{\text {th }}$ International Pediatric Emergency Medicine and Intensive Care Congress and 8th Pediatric Emergency Medicine and Intensive Care Nursing Congress, 16-19 December 2015, Antalya, Turkey.

Address for Correspondence:

Ahmet Kağan Özkaya, Division of Pediatric Emergency Unit, Department of Pediatrics, Karadeniz Technical University School of Medicine, Trabzon, Turkey E-mail: kaganozkaya@yahoo.com

oCopyright 2017 by Emergency Physicians Association of Turkey - Available online at www.jemcr.org 
Table 1. Features of the anticholinergic syndrome

$\begin{array}{ll}\text { Central nervous system symptoms } & \text { Peripheral symptoms } \\ \text { Altered mental status } & \text { Tachycardia } \\ \begin{array}{l}\text { Changes in mood (anxiety, fear, } \\ \text { and euphoria) }\end{array} & \text { Dry and erythematous skin } \\ \text { Hallucinations } & \text { Mydriasis } \\ \text { Ataxia } & \text { Dry mucosa } \\ \text { Seizures, coma, and death } & \text { Hyperthermia } \\ & \text { Decreased bowel sounds } \\ & \text { Urinary retention }\end{array}$

cataract in the left eye, flushing of the face, dry oral mucosa, spasticity in all extremities, and wheezing on both sides of the chest. Because drug-related side-effects or an allergic reaction to the eye drops were the suspected causes of the symptoms, pheniramine maleate (1 $\mathrm{mg} / \mathrm{kg}$ ) and methylprednisolone $(1 \mathrm{mg} / \mathrm{kg})$ were administered, and both eyes were washed with normal saline. After $1 \mathrm{~h}$, the patient's symptoms deteriorated, with increases in body temperature $\left(38.6^{\circ} \mathrm{C}\right)$, pulse (210 beats $/ \mathrm{min})$, respiratory rate (56 breaths $/ \mathrm{min})$, and blood pressure $(80 / 50 \mathrm{mmHg}$ ) and a decrease in oxygen saturation (92\%) when breathing ambient air. Symptoms of the anticholinergic syndrome were observed, including respiratory distress, dryness of the skin, decreased levels of saliva and sweat, eyeball depression, reduced turgor pressure, urinary retention, and excessive agitation. Laboratory examination revealed the levels of the following parameters: $\mathrm{Hb} 10.2$ $\mathrm{g} / \mathrm{dL}$, white blood count $15,100 / \mathrm{mm}^{3}$, platelet count $454,000 / \mathrm{mm}^{3}$, blood glucose $220 \mathrm{mg} / \mathrm{dL}$, blood gas pH 7.05, $\mathrm{pCO}_{2} 41 \mathrm{mmHg}, \mathrm{pO}_{2}$ $86.7 \mathrm{mmHg}, \mathrm{HCO}_{3} 10.4 \mathrm{mEq} / \mathrm{L}, \mathrm{BE}-17.4 \mathrm{mEq} / \mathrm{L}$, and blood lactate 14 $\mathrm{mg} / \mathrm{dL}$. Other biochemical parameters were normal. Sinus tachycardia was revealed by electrocardiography. Chest radiography revealed peribronchial thickening and perihilar lung consolidation.

Normal saline $(20 \mathrm{~mL} / \mathrm{kg})$ was administered two times as a bolus and then as an intravenous fluid at $2000 \mathrm{~mL} / \mathrm{m}^{2}$. Other supportive treatments were given due to shock, and midazolam $(0.1 \mathrm{mg} / \mathrm{kg})$ was administered for sedation. Ceftriaxone and oseltamivir were administered to combat the lung infection and to treat possible influenza, and physostigmine was obtained for use if necessary, but was not required. The patient was admitted to the pediatric intensive care unit for further observation and treatment. At follow-up, the patient's tachypnea, breathing pattern, tachycardia, and body temperature had recovered, and his anticholinergic symptoms had regressed. Additionally, his metabolic acidosis and hyperlactatemia had dramatically improved. On the second day of observation, no anticholinergic symptoms were observed. The patient was discharged 6 days later.

Written informed consent was obtained from patient's parents who participated in this case.

\section{Discussion}

Topical eye drops are widely used to facilitate cycloplegia and retinal examination for mydriasis, and phenylephrine and atropine- like agents are commonly employed agents. These agents can be toxic when administered in high concentrations or at frequent intervals and can pass into the systemic circulation through the skin, nasal mucosa, cornea, conjunctiva, or aqueous humor $(1,2)$. Life-threatening side-effects or death are rare, but are mostly seen in infants or young children when they do occur. Atropine or atropinelike drugs are competitor antagonists of acetylcholine that interact with muscarinic receptors. Cases of anticholinergic poisoning following the administration of topical eye drops containing atropine or atropine-like substances have been previously reported $(1,3-5)$. When a patient has nonreactive dilated pupils, tachycardia, flushed skin, dry mucosa, hyperthermia, urinary retention, and changes in consciousness, anticholinergic poisoning should be considered $(3,4,6)$. Decreased sweat levels, reduction in bowel sounds, visual and auditory hallucinations, delirium, seizures, coma, and even death may also represent part of the anticholinergic toxidrome (Table 1) (6). To the best of our knowledge, no previous reports have described central or peripheral anticholinergic effects with eye drops containing only tropicamide in pediatric patients. Although antihistamine was given because of the initial diagnosis of an allergic drug reaction, the presence of central and peripheral anticholinergic effects during the initial reaction stages suggested systemic poisoning with tropicamide. No drug-drug and drug-allergy interactions or content duplication between topiramate, tropicamide, and pheniramine maleate have been determined, and delirium and anticholinergic symptoms are not expected conditions in epilepsy and cerebral palsy (5). Considering all the characteristics of our patient, we think that the case is compatible with anticholinergic poisoning. Indeed, recognizing toxidromes in the early stages of poisoning cases is essential. However, systemic side-effects related to topical eye drop administration may not be recognized or may be ignored by the patient's family or physicians. It is therefore essential to know the signs and symptoms of the toxidrome to begin appropriate treatment.

The use of physostigmine to treat anticholinergic intoxication is controversial (7). However, if life-threatening conditions and severe central nervous system dysfunction such as seizures, coma, or cardiac involvement are observed, physostigmine may be useful. Physostigmine is a reversible anticholinesterase inhibitor in both the peripheral and central nervous systems. Physicians should be wary of administering physostigmine to patients with asthma, ileus, epilepsy, or dysrhythmia because it may exacerbate these diseases (7). Physostigmine is administered intravenously over $5 \mathrm{~min}$ at a dose of $0.04-2$ $\mathrm{mg} / \mathrm{kg}$, which may be repeated after 10-40 min if necessary (8).

\section{Conclusion}

In this case, the patient was exposed to a higher than recommended dose of tropicamide in a short period of time. At a time, one or two drops of tropicamide should be administered to each eyeball while compressing the lacrimal duct to avoid systemic effects, and this may be repeated after $5 \mathrm{~min}$. The undesirable effects of tropicamide may be stronger because it is found in the same drugs as cycloplegic agents. Therefore, mydriatic eye drops should be used for ophthalmological examination or any other procedure at the appropriate dose and under the supervision of an ophthalmologist. 
Informed Consent: Written informed consent was obtained from patient's parents who participated in this case.

Peer-review: Externally peer-reviewed.

Author contributions: Concept - A.K.Ö., S.S.G., Ö.T.K., R.D.Y., H.L.Y.; Design A.K.Ö., H.L.Y.; Supervision - A.K.Ö., H.L.Y., R.D.Y.; Resource - A.K.Ö., S.S.G., Ö.T.K., R.D.Y., H.L.Y.; Materials - A.K.Ö., S.S.G., Ö.T.K., R.D.Y., H.L.Y.; Data Collection and/ or Processing - A.K.Ö., S.S.G., Ö.T.K.; Analysis and/or Interpretation - A.K.Ö., H.L.Y.; Literature Search - A.K.Ö., H.L.Y.; Writing - H.L.Y., A.K.Ö.; Critical Reviews - H.L.Y., A.K.Ö., R.D.Y.

Conflict of Interest: The authors declared no conflict of interest.

Financial Disclosure: The authors declared that this study has received no financial support.

\section{References}

1. Labetoulle M, Frau É, Le Jeunne C. Systemic adverse effects of topical ocular treatments. Presse Med 2005; 34: 589-95. [CrossRef]
2. Alpay A, Ermis B, Ugurbas SC, Battal F, Sagdik HM. The local vasoconstriction of infant's skin following instillation of mydriatic eye drops. Eur J Clin Pharmacol 2010; 66: 1161-4. [CrossRef]

3. Coco TJ, Liebelt EL. General Approach to Poisoning. In Baren JM, Rothrock SG, Brennan JA, Brown L, eds. Pediatric Emergency Medicine. Philadelphia: Saunders, Elsevier PA; 2008. p.106-14. [CrossRef]

4. Reilly KM, Chan L, Mehta NJ, Salluzzo RF. Systemic toxicity from ocular homatropine. Acad Emerg Med 1996; 3: 868-71. [CrossRef]

5. Micromedex ${ }^{\oplus}$ 2.0. Truven Health Analytics, Greenwood Village, Colorado, USA. Available from: http://www.micromedexsolutions.com/

6. Brunner GA, Fleck S, Pieber TR, Lueger A, Kaufmann P, Smolle KH, et al. Near fatal anticholinergic intoxication after routine fundoscopy. Intensive Care Med 1998; 24: 730-1. [CrossRef]

7. Burns MJ, Linden CH, Graudins A, Brown RM, Fletcher KE. A comparison of physostigmine and benzodiazepines for the treatment of anticholinergic poisoning. Ann Emerg Med 2000; 35: 374-81. [CrossRef]

8. Lee AC, So KT. Acute anticholinergic poisoning in children. Hong Kong Med J 2005; 11: 520-3. 